\title{
3 Research Square

\section{Trajectories of hospitalization in three groups of patients with incurable gastric cancer identified by hierarchical clustering: A retrospecitve analysis}

\author{
Yasuko Murakawa ( $\nabla$ murakawa-ya995@miyagi-pho.jp ) \\ Miyagi Cancer Center https://orcid.org/0000-0002-4654-8763 \\ Masato Sakayori \\ Miyagi Cancer Center
}

Kazunori Otsuka

Miyagi Cancer Center

\section{Research article}

Keywords: incurable gastric cancer, overall survival, quality of life, hospitalization, planned hospitalization, unplanned hospitalization

Posted Date: January 15th, 2020

DOI: https://doi.org/10.21203/rs.2.20848/v1

License: (a) (1) This work is licensed under a Creative Commons Attribution 4.0 International License. Read Full License

Version of Record: A version of this preprint was published at Journal of Cancer Science and Clinical Therapeutics on January 1st, 2020. See the published version at https://doi.org/10.26502/jcsct.5079090. 


\section{Abstract}

Purpose: The therapeutic goal for advanced solid malignancies is not to achieve cure but to prolong survival and maintain quality of life (QOL). To date, no study has reported the trajectory of the QOL throughout the clinical course of a patient with advanced malignancy. As hospitalization is considered a predictor of QOL, we retrospectively analyzed the trajectory of hospitalization in patients with incurable gastric cancer throughout the clinical course.

Methods: The data of 85 patients with incurable gastric cancer were collected, including age, sex, Eastern Cooperative Oncology Group (ECOG) Performance Status (PS), treatment, histology, sites of metastases at first consultation, planned and unplanned hospitalization throughout the clinical course, and overall survival (OS). We ranked the patients by OS and hospitalization using a hierarchical clustering analysis.

Results: Three clusters were identified corresponding to short, intermediate, and long OS/hospitalization (Clusters 1, 2, and 3, respectively). Patients in Cluster 3 were more likely to have an ECOG PS of 0-2 and receive palliative chemotherapy than the other clusters. No other differences in histology, age, sex, and or extra-peritoneal metastasis sites were observed between the three groups. In Cluster 3, planned hospitalization accumulated gradually during the early clinical phase, while unplanned hospitalization accumulated rapidly in later phases.

Conclusions: No specific characteristics were associated with short, intermediate, and long OS/hospitalization. Patients in the long OS/hospitalization group exhibited a rapid accumulation of unplanned hospitalization during the latter clinical course. Further research is needed to identify specific predictors of and measures to avoid a long OS/hospitalization.

\section{Background}

The therapeutic goal for a patient with an advanced solid malignancy is to prolong survival and maintain the quality of life (QOL), rather than to achieve a curative outcome [1]. Although many studies have reported the overall survival (OS) outcomes of patients with incurable cancer, changes in the QOL throughout the clinical course have not been evaluated.

Eastern Cooperative Oncology Group (ECOG) performance status (PS) and palliative chemotherapy status are generally considered prognostic factors for OS in patients with advanced solid malignancies. Several studies have shown that palliative chemotherapy generally does not prolong survival in patients with solid malignancies who have a poor ECOG PS [2] [3]. The American Society of Clinical Oncology advocates withholding palliative chemotherapy from patients with solid tumors and an ECOG PS of 3-4, and instead recommends best supportive care (BSC) [4]. However, in our previous study [5], almost half of patients with an ECOG PS of 3-4 selected palliative chemotherapy, while patients with an ECOG PS of 02 did not experience prolonged survival with palliative chemotherapy when compared to patients with an ECOG PS of $3-4$. 
Typically, QOL is evaluated using a questionnaire, and many studies that address changes in QOL are limited to specific phases of the clinical course. However, hospitalization is considered a predictor of QOL [6]. This variable can be divided into planned and unplanned hospitalization, of which the latter is generally considered unfavorable for patients. To date, no study has reported the trajectory of hospitalization throughout the clinical course.

Gastric cancer was the fifth most common malignancy and the third leading cause of cancer-related mortality in 2018, according to Global Cancer Statistics [7]. Gastric cancer is even more common in Japan, with the second highest incidence and third highest mortality rate of all cancers according to a short-term projection method applied by the Projected Cancer Statistics 2018 [8]. Therefore, the first aim of this study was to classify patients with incurable gastric cancer according to OS and hospitalization and clarify the characteristics of the resulting groups. The second aim was to analyze the trajectory of hospitalization throughout the clinical course.

\section{Methods}

\section{Patients}

We retrospectively evaluated 85 patients with incurable gastric cancer who attended the Miyagi Cancer Center (Natori, Japan) between May 2014 and February 2018 and died up to May 2019. This study collected the following data: age, sex, ECOG PS, treatment (palliative chemotherapy vs. BSC), histology, sites of metastases at first consultation, OS, hospitalization (planned and unplanned), and the trajectory of hospitalization.

Histologically, patients were divided into two types: intestinal type or diffuse type. The mixed type, which included both the intestinal and diffuse types, was categorized as the latter. The sites of metastases were the peritoneum, liver, lymph nodes, bone, anastomotic site/remaining stomach, lung/pleura, adrenal gland, others (ovary, skin, and brain), and locally advanced disease. The oncologist explained the benefits and limitations of palliative chemotherapy and BSC to all patients during their first consultation.

Statistical analyses

We used a hierarchical clustering analysis method to classify the patients based on OS and hospitalization. We then used the square of the Euclidean distance dissimilarity coefficient to determine the similarities or differences between patients. The results of the clustering analysis are presented in a dendrogram chart. The ECOG PS, treatment, histology, age, sex, and sites of metastases in the groups were compared using the chi-square test. A two-tailed $P$-value of $<0.05$ was considered significant. OS curves were estimated using the Kaplan-Meier method, and comparisons of survival between clusters 
were performed using the log-rank test. All statistical analyses were performed using the Statistical Package for the Social Science for Windows (version 24; SPSS Inc., Chicago, IL, USA).

\section{Results}

The cluster analysis with OS and hospitalization yielded three groups of patients (Fig. 1) which are depicted in a scatter plot (Fig. 2). The Kaplan-Meier analysis revealed that Cluster 3 had the longest OS of the three clusters (median OS: Cluster 3 vs. Cluster 1 and Cluster 2; 33.2 vs. 3.7 and 13.2 months, respectively; $P<0.001$ for both). Cluster 2 had a longer OS than Cluster 1 (median OS: 13.2 vs. 3.7 months; $P<0.001$; Fig. 3). Cluster 3 also had the longest hospitalization (mean hospitalization: Cluster 3 vs. Cluster 1 and Cluster 2; 165 vs. 55 and 80 days, respectively; $P<0.001$ for both), and Cluster 2 had a longer hospitalization than Cluster 1 (mean hospitalization: 80 vs. 55 days; $P<0.05$ ). Consequently, Clusters 1, 2 , and 3 were characterized as the short, intermediate, and long OS/hospitalization groups, respectively (Fig. 4).

An analysis of the clinical characteristics revealed that more patients in Cluster 3 had an ECOG PS of $0-2$ compared to those in Clusters 1 and 2 (ECOG PS 0-2/3-4: Cluster 1, 25/13; Cluster 2, 32/6; Cluster 3, $9 / 0 ; P<0.05)$. Patients in Cluster 3 were also more likely to have received palliative chemotherapy (palliative chemotherapy/BSC: Cluster 1, 23/15; Cluster 2, 35/3; Cluster 3, 9/0; $P<0.01$ ). Patients in Cluster 2 were less likely to present with metastasis in the peritoneum (metastasis in peritoneum, +/-: Cluster 1 , 22/16; Cluster 2, 11/27; Cluster 3, 5/4; $P<0.05$ ). There were no differences in histology, age, sex, or other sites of metastases between the three groups (Table 1 ).

Next, we analyzed planned and unplanned hospitalization in the three groups (Fig. 4). Here, planned hospitalization referred to a short-term stay for palliative chemotherapy, while unplanned hospitalization involved cancer-related symptoms. Cluster 3 had a longer duration of planned hospitalization than Clusters 1 and 2 (mean: 67 vs. 9 and 29 days, respectively; $P<0.001$ for both), while Cluster 2 had a longer duration than Cluster 1 (mean: 29 vs. 9; $P<0.001$ ). Cluster 3 also had a longer duration of unplanned hospitalization than Clusters 1 and 2 (mean: 80 vs. 46 and 55 days, respectively; $P<0.05$ for both), whereas there was no significant difference between Clusters 1 and 2.

The trajectory of hospitalization was then analyzed in each group (Fig. 5). Cluster 3 exhibited a gradual accumulation of planned hospitalization during the early phase, followed by a rapid accumulation of unplanned hospitalization. Cluster 1 experienced almost entirely unplanned hospitalization. Cluster 2 exhibited an intermediate pattern between those of Clusters 1 and 3 .

\section{Discussion}

ECOG PS and palliative chemotherapy have been reported as independent prognostic factors for OS [9] [10]. Specifically, patients with a good ECOG PS are recommended to undergo palliative chemotherapy [11], and a meta-analysis of randomized controlled trials of advanced gastric cancer reported that 
chemotherapy extended OS by 6.7 months relative to BSC [12]. In this study, we accordingly classified patients into clusters and determined that patients in Cluster 3 were most likely to have an ECOG PS of 0-2 and to have received palliative chemotherapy compared to the other clusters. We noted that metastases of the peritoneum, lymph nodes, bone, lung, ovary, and brain have also been identified as potential prognostic factors for OS [13] [14] [15] [16] [17]. In this study, only the likelihood of peritoneal metastasis differed, with a higher incidence in Cluster 2 relative to the other clusters. These results might be attributable to the use of data collected at the first consultation which did not account for newly developed metastases.

Lauren's histological classification classifies gastric cancers into two histological subtypes, intestinal and diffuse, as this variable has been reported to predict survival and responses to chemotherapy [18] [19]. In this study, however, we did not observe a significant association of either type with a long OS. We noted that the histological diagnoses in our cases were generally made from biopsy rather than surgical samples. Therefore, the diagnoses might not have reflected the true nature of the disease. In contrast to histology, age is not generally considered a prognostic factor in patients with advanced gastric cancer, and several studies reported that palliative chemotherapy is equally tolerable and effective in older and younger patients [20] [21]. Consistent with those observations, we did not observe an association of age with a long OS.

QOL has become increasingly important as the number of newly diagnosed patients with cancer continues to increase. Over time, improvements in the management of certain chemotherapy-associated toxicities have led to a shift from issues of physical QOL to issues of psychosocial QOL [22]. The most widely used measures of cancer-specific health-related QOL are the European Organization for Research and Treatment Quality of Life Questionnaire, version 3.0 (EORTC-QLQ-C30), McGill QOL questionnaire, and the EuroQol-5D (EQ-5D) [23]. These questionnaires have been used to investigate the trajectory of QOL among advanced-stage cancer patients in several studies [24] [25]. However, the physical and/or mental condition of the patient may make it difficult to administer a questionnaire, particularly if the patient has a poor ECOG PS and has reached the end-of-life stage. Moreover, many studies of the changes in QOL experienced by patients with incurable cancer patients are limited to specific clinical course phases, such as limited cycles of chemotherapy or phase III chemotherapy trials [26] [27].

Hospitalization has negative effects on the QOL. However, this option is needed in many situations. Planned hospitalization is necessary for the administration of palliative chemotherapy, radiation therapy, and surgery. In contrast, unplanned hospitalization is generally needed to treat chemotherapy-related toxicities and cancer-related symptoms and is especially undesirable for patients [28] [29]. Patients with end-stage disease exhibit a significant loss of QOL during hospitalization [30]. Notably, one previous study suggested the importance of an optimal discharge-planning system and early referral to palliative care to prevent hospital readmission [31].

The Japanese healthcare system features a unique combination of characteristics that have led to the overuse of tests and drugs, as well as relatively longer hospital stays than those in other countries [32]. 
One study reported that $27 \%$ of older patients in Japan experienced $\geq 90$ days of hospitalization during their last year of life [33]. For patients with incurable malignancies, decision making regarding treatment is complex; therefore, oncologists need to assist the patients and their families. [34] In decision making, not only OS but the trajectory of QOL throughout the clinical course might be helpful.

In this study, a long OS was shown to correlate strongly with hospitalization. However, the trajectory of hospitalization tended to accumulate rapidly due to unplanned hospitalization during the last phase of the clinical course.

The major strength of this study was the classification of patients with incurable gastric cancer into three groups by OS/hospitalization as well as our analysis of various characteristics of these groups, including planned and unplanned hospitalization.

This study has several limitations. We used planned/unplanned hospitalization as a predictor of QOL; however, other factors are also associated with psychosocial QOL. In this study, predicting the length of OS/hospitalization was challenging. In the future, predicting OS and the trajectory of QOL throughout the clinical course is essential.

\section{Conclusion}

An ECOG PS of $0-2$ and palliative chemotherapy were significantly associated with a long OS and hospitalization duration in our analysis. However, these factors were not specific to a particular group. Patients in the long OS/hospitalization group tended to accumulate unplanned hospitalization during the last phase of the clinical course. Further research is needed to identify the specific factors predictive of a long OS/hospitalization and the measures needed to avoid a long unplanned hospitalization.

\section{Declarations}

\section{Availability of data and materials}

The raw data used in this study have been shared in Figshare (DOI: 10.6084/m9.figshare.10278155.)

\section{Compliance with ethical standards}

\section{Ethics approval and consent to participate}

All procedures performed in studies involving human participants were in accordance with the ethical standards of the institutional and/or national research committee (Miyagi Cancer Center, reference number: No. 4, March 13, 2019) and with the 1964 Declaration of Helsinki and its later amendments or 
comparable ethical standards. This article does not contain any studies with animals performed by any of the authors.

\section{Informed consent}

According to the local ethics policy for the retrospective analysis of anonymized in-house clinical data, information about this study and a means of opting out were posted on a website. Informed consent was obtained from all patients included in the study, and participants were not required to provide additional written or verbal consent.

\section{Consent for publication}

Not applicable

\section{Competing Interests}

The authors declare that they have no competing interests

An interim report of this work was presented as a poster at the $18^{\text {th }}$ Japanese Society of Medical Oncology Annual Meeting, Kyoto, 2019.

\section{Authors' contributions}

All authors made substantial contributions to the conception and design of this study. MS and KO collected the medical data, and YM analyzed the data and drafted the manuscript. All authors critically revised the manuscript for important intellectual content and gave final approval of the version to be published.

\section{Acknowledgements}

Not applicable.

\section{Funding}

Not applicable. 


\section{References}

1. Browner I, Carducci MA (2005) Palliative chemotherapy: Historical perspective, applications, and controversies. Semin Oncol 32:145-155. https://doi.org/10.1053/j.seminoncol.2004.11.014

2. Wheatley-Price P, Ali M, Balchin K, Spencer J, Fitzgibbon E, Cripps C (2014) The role of palliative chemotherapy in hospitalized patients. Curr Oncol 21:187-192. https://doi.org/10.3747/co.21.1989

3. Crosara Teixeira M, Marques DF, Ferrari AC, Alves MF, Alex AK, Sabbaga J et al (2015) The effects of palliative chemotherapy in metastatic colorectal cancer patients with an ECOG performance status of 3 and 4. Clin Colorectal Cancer 14:52-57. https://doi.org/10.1016/j.clcc.2014.09.010

4. Schnipper LE, Smith TJ, Raghavan D, Blayney DW, Ganz PA, Mulvey TM et al (2012) American Society of Clinical Oncology identifies five key opportunities to improve care and reduce costs: The top five list for oncology. J Clin Oncol 30:1715-1724. https://doi.org/1200/JC0.2012.42.8375

5. Murakawa Y, Sakayori M, Otsuka K (2019) Impact of palliative chemotherapy and best supportive care on overall survival and length of hospitalization in patients with incurable Cancer: A 4-year single institution experience in Japan. BMC Palliat Care 18:45. https://doi.org/10.1186/s12904-0190428-3

6. Prince RM, Powis M, Zer A, Atenafu EG, Krzyzanowska MK (2019) Hospitalisations and emergency department visits in cancer patients receiving systemic therapy: Systematic review and metaanalysis. Eur J Cancer Care (Engl) 28:e12909. https://doi.org/10.1111/ecc.12909

7. Bray F, Ferlay J, Soerjomataram I, Siegel RL, Torre LA, Jemal A (2018) Global cancer statistics 2018: GLOBOCAN estimates of incidence and mortality worldwide for 36 cancers in 185 countries. CA Cancer J Clin 68:394-424. https://doi.org/10.3322/caac.21492

8. Katanoda K, Kamo K, Saika K, Matsuda T, Shibata A, Matsuda A et al (2014) Short-term projection of cancer incidence in Japan using an age-period interaction model with spline smoothing. Jpn J Clin Oncol 44:36-41. https://doi.org/10.1093/jjco/hyt163

9. Fuchs CS, Muro K, Tomasek J, Van Cutsem E, Cho JY, Oh SC et al (2017) Prognostic factor analysis of overall survival in gastric cancer from two phase III studies of second-line ramucirumab (REGARD and RAINBOW) using pooled patient data. J Gastric Cancer 17:132-144. https://doi.org/10.5230/jgc.2017.17.e16

10. Zeng WJ, Hu WQ, Wang LW, Yan SG, Li JD, Zhao HL (2014) Long term follow up and retrospective study on 533 gastric cancer cases. BMC Surg 14:29. https://doi.org/10.1186/1471-2482-14-29

11. Peppercorn JM, Smith TJ, Helft PR, Debono DJ, Berry SR, Wollins DS et al (2011) American society of clinical oncology statement: Toward individualized care for patients with advanced cancer. J Clin Oncol 29:755-760. https://doi.org/10.1200/JC0.2010.33.1744

12. Wagner AD, Grothe W, Behl S, Kleber G, Grothey A, Haerting J et al (2017) Chemotherapy for advanced gastric cancer. Cochrane Database Syst Rev 8:CD004064. https://doi.org/10.1002/14651858 
13. Mizrak Kaya D, Nogueras-González GM, Harada K, Amlashi FG, Roy-Chowdhuri S, Estrella JS et al (2018) Risk of peritoneal metastases in patients who had negative peritoneal staging and received therapy for localized gastric adenocarcinoma. J Surg Oncol 117:678-684. https://doi.org/10.1002/jso.24912

14. Deng J, Sun D, Pan Y, Zhang L, Zhang R, Wang D et al (2012) Ratio between negative and positive lymph nodes is suitable for evaluation the prognosis of gastric cancer patients with positive node metastasis. PLoS One 7:e43925. https://doi.org/10.1371/journal.pone.0043925

15. Koo DH, Ryu MH, Ryoo BY, Seo J, Lee MY, Chang HM et al (2015) Improving trends in survival of patients who receive chemotherapy for metastatic or recurrent gastric cancer: 12 years of experience at a single institution. Gastric Cancer 18:346-353. https://doi.org/10.1007/s10120-014-0385-8

16. Uyeturk U, Arslan SH, Bal O, Arslan UY, Oksuzoglu OB (2013) Isolated ovarian metastasis of gastric cancer: Krukenberg tumor. Contemp Oncol (Pozn) 17:515-519. https://doi.org/10.5114/wo.2013.37542

17. Kraszkiewicz M, Wydmanski J (2014) Brain metastases from stomach cancer - The role of different treatment modalities and efficacy of palliative radiotherapy. Rep Pract Oncol Radiother 20:32-37. https://doi.org/10.1016/j.rpor.2014.08.003

18. Jimenez Fonseca P, Carmona-Bayonas A, Hernández R, Custodio A4, Cano JM, Lacalle A et al (2017) Lauren subtypes of advanced gastric cancer influence survival and response to chemotherapy: Realworld data from the AGAMENON National Cancer Registry. Br J Cancer 117:775-782. https://doi.org/10.1038/bjc.2017.245

19. Ma J, Shen H, Kapesa L, Zeng S (2016) Lauren classification and individualized chemotherapy in gastric cancer. Oncol Lett 11:2959-2964. https://doi.org/10.3892/ol.2016.4337

20. Berger AK, Zschaebitz S, Komander C, Jäger D, Haag GM (2015) Palliative chemotherapy for gastroesophageal cancer in old and very old patients: A retrospective cohort study at the National Center for Tumor Diseases, Heidelberg. World J Gastroenterol 21:4911-4918. https://doi.org/10.3748/wjg.v21.i16.4911

21. Kim ST, Park KH, Oh SC, Seo JH, Shin SW, Kim JS et al (2012) Is chemotherapy in elderly patients with metastatic or recurrent gastric cancer as tolerable and effective as in younger patients? Asia Pac J Clin Oncol 8:194-200. https://doi.org/10.1111/j.1743-7563.2011.01501.x

22. Carelle N, Piotto E, Bellanger A, Germanaud J, Thuillier A, Khayat D (2002) Changing patient perceptions of the side effects of cancer chemotherapy. Cancer 95:155-163. https://doi.org/10.1002/cncr.10630

23. Davis MP, Hui D (2017) Quality of life in palliative care. Expert Rev Qual Life Cancer Care 2:293-302. https://doi.org/10.1080/23809000.2017.1400911

24. Giesinger JM, Wintner LM, Oberguggenberger AS, Gamper EM, Fiegl M, Denz H et al (2011) Quality of life trajectory in patients with advanced cancer during the last year of life. J Palliat Med 14:904-912. https://doi.org/10.1089/jpm.2011.0086. 
25. Kypriotakis G, Vidrine DJ, Francis LE, Rose JH (2016) The longitudinal relationship between quality of life and survival in advanced stage cancer. Psychooncology 25:225-231. https://doi.org/10.1002/pon.3846

26. Tantoy IY, Cooper BA, Dhruva A, Cataldo J, Paul SM, Conley YP et al (2018) Quality of life of patients with gastrointestinal cancers undergoing chemotherapy. Qual Life Res 27:1865-1876. https://doi.org/10.1007/s11136-018-1860-1

27. Hamaker ME, Schulkes KJ, Ten Bokkel Huinink D, van Munster BC, van Huis LH, van den Bos F (2017) Evaluation and reporting of quality of life outcomes in phase III chemotherapy trials for poor prognosis malignancies. Qual Life Res 26:65-71. https://doi.org/10.1007/s11136-016-1360-0

28. Weaver C, Schiech L, Held-Warmkessel J, Kedziera P, Haney E, DiLullo G et al (2006) Risk for unplanned hospital readmission of patients with cancer: Results of a retrospective medical record review. Oncol Nurs Forum 33:E44-52. https://doi.org/10.1188/06.ONF.E44-E52

29. Whitney RL, Bell JF, Tancredi DJ, Romano PS, Bold RJ, Wun T et al (2019) Unplanned hospitalization among individuals with cancer in the year after diagnosis. J Oncol Pract 15:e20-29. https://doi.org/10.1200/JOP.18.00254

30. Bužgová R, Sikorová L, Kozáková R, Jarošová D (2017) Predictors of change in quality of life in patients with end-stage disease during hospitalization. J Palliat Care 32:69-76. https://doi.org/10.1177/0825859717724687

31. Granda-Cameron C, Behta M, Hovinga M, Rundio A, Mintzer D (2015) Risk factors associated with unplanned hospital readmissions in adults with cancer. Oncol Nurs Forum 42:E257-268. https://doi.org/10.1188/15.0NF.E257-E268

32. Nomura H, Nakayama T (2005) The Japanese healthcare system. BMJ 331:648-649. https://doi.org/10.1136/bmj.331.7518.648

33. Ishizaki T, Shimmei M, Fukuda H, Oh EH, Shimada C, Wakui T et al (2017) Cumulative number of hospital bed days among older adults in the last year of life: A retrospective cohort study. Geriatr Gerontol Int 17:737-743. https://doi.org/10.1111/ggi.12777

34. Bakitas M, Kryworuchko J, Matlock DD, Volandes AE (2011) Palliative medicine and decision science: The critical need for a shared agenda to foster informed patient choice in serious illness. $J$ Palliat Med 14:1109-1116. https://doi.org/10.1089/jpm.2011.0032.

\section{Figures}




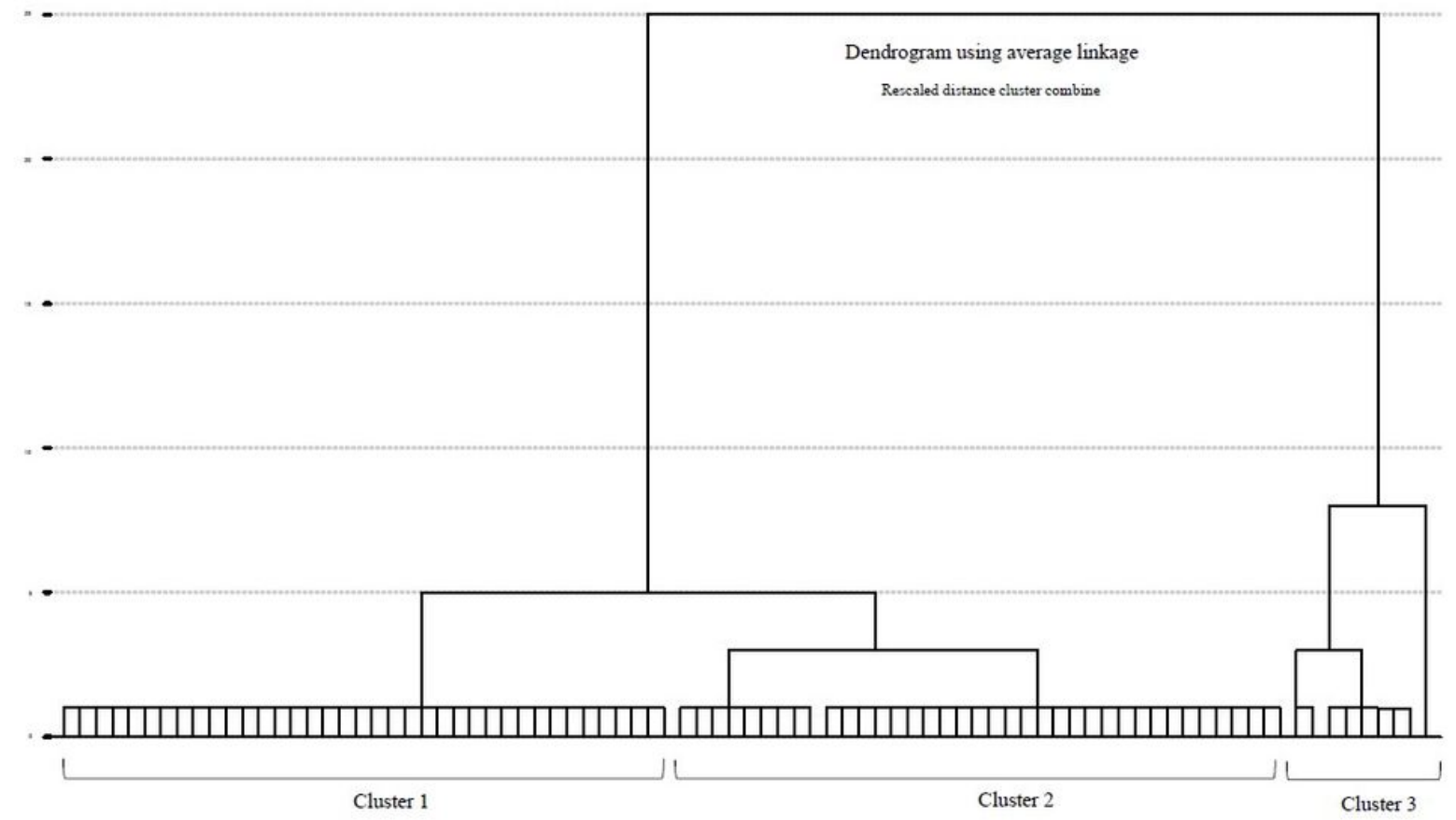

Figure 1

Dendrogram of patients with incurable gastric cancer categorized by overall survival and hospitalization

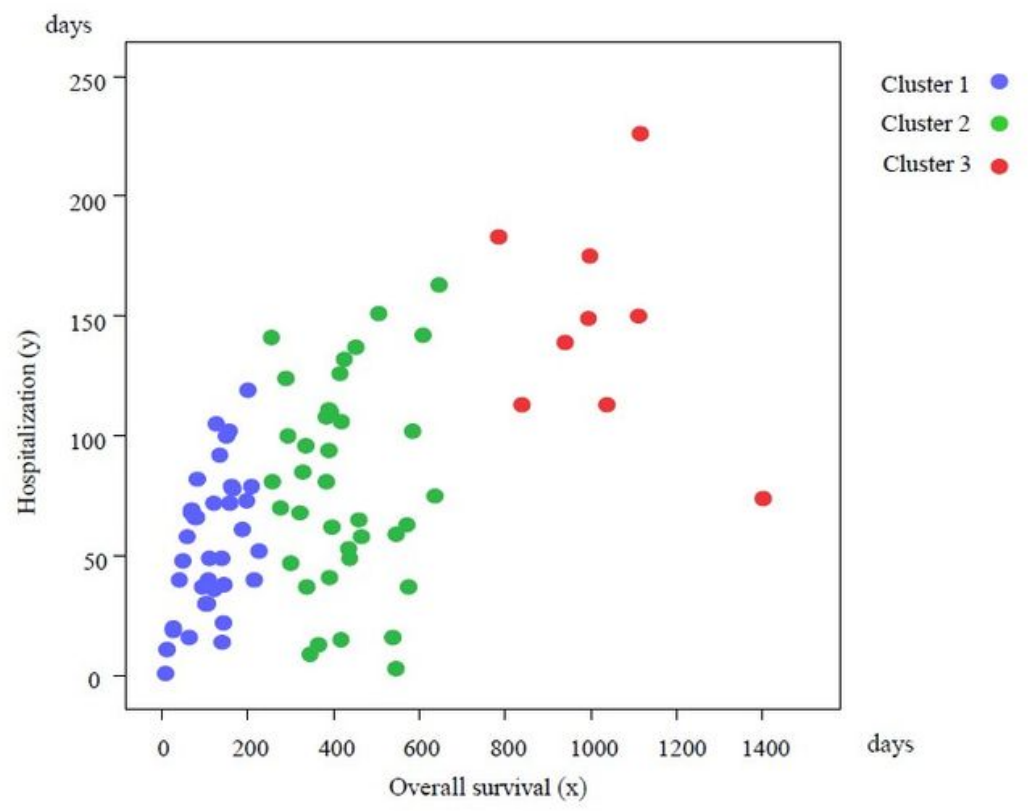

Figure 2

Correlation between overall survival and hospitalization in patients with incurable gastric cancer 


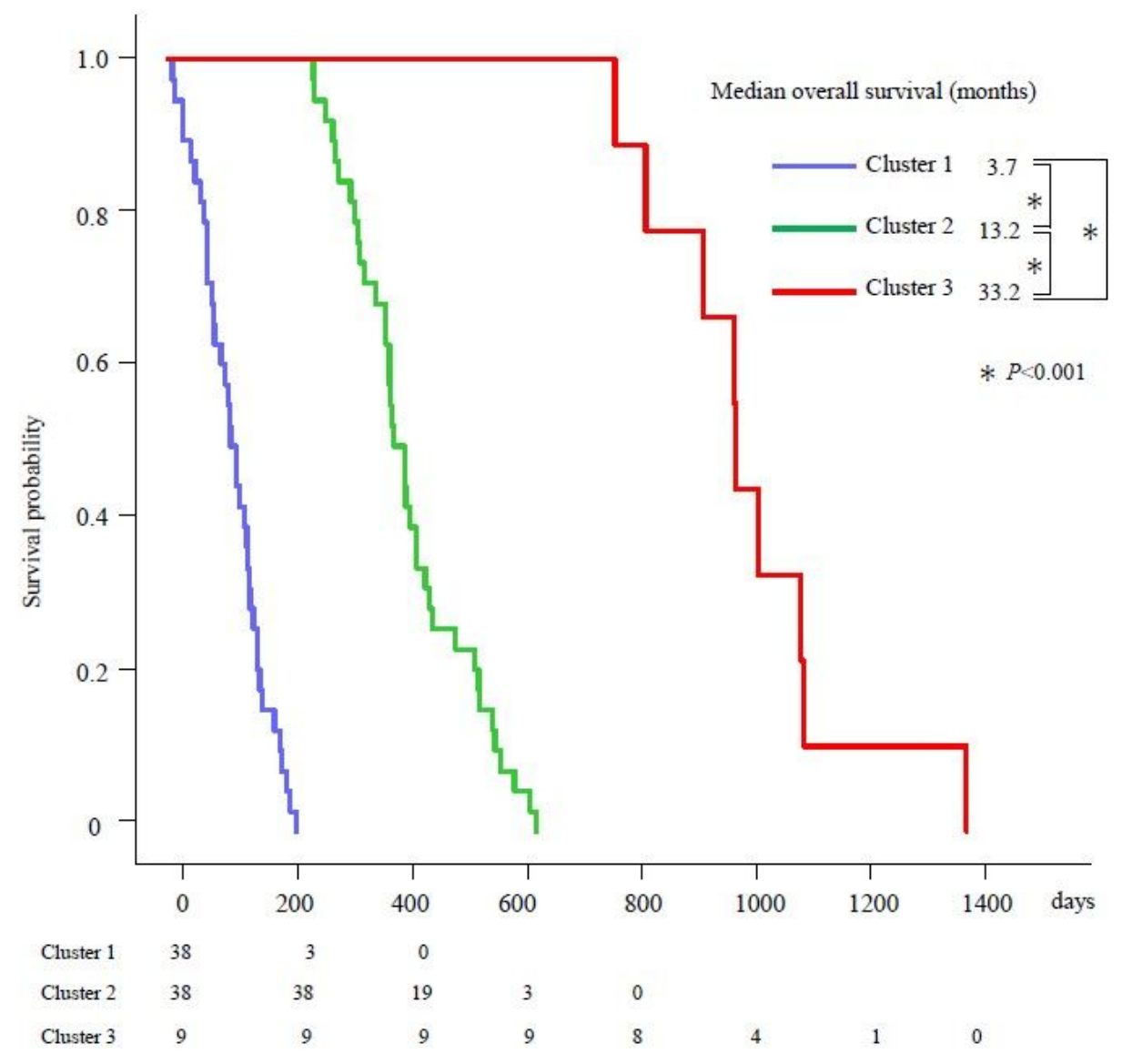

Figure 3

Kaplan-Meier curves of estimated overall survival in three groups of patients with incurable gastric cancer

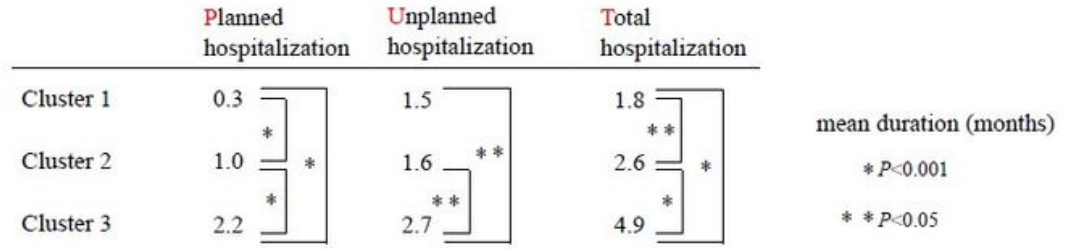

days

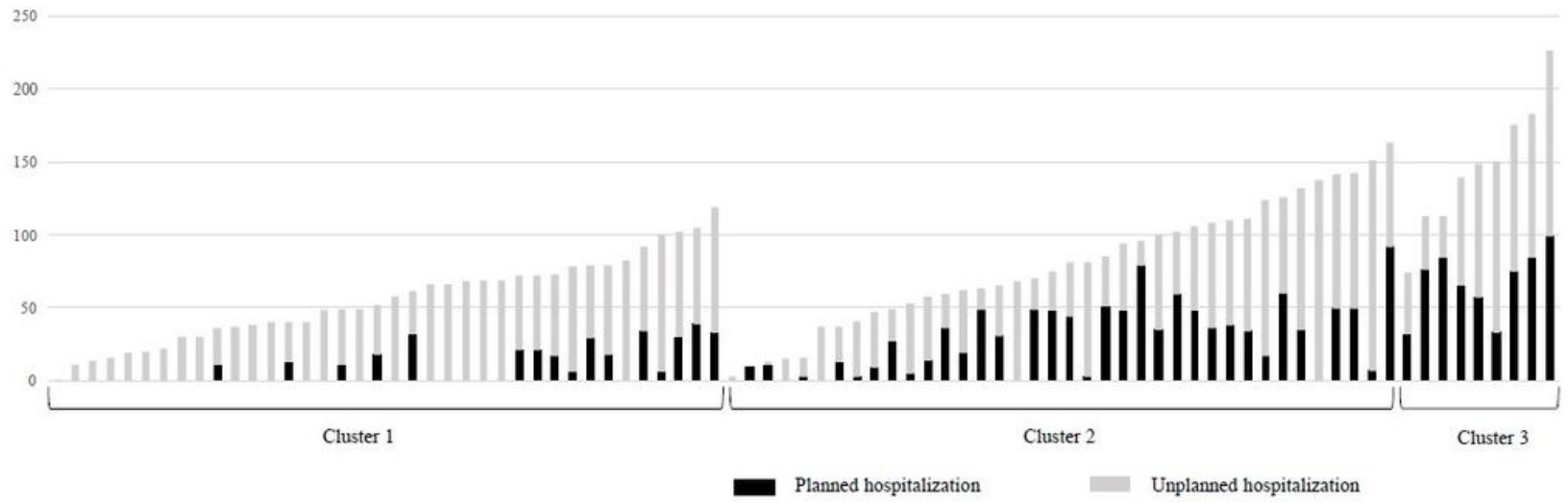

Page $12 / 13$ 


\section{Figure 4}

Planned and unplanned hospitalization in three groups of patients with incurable gastric cancer days
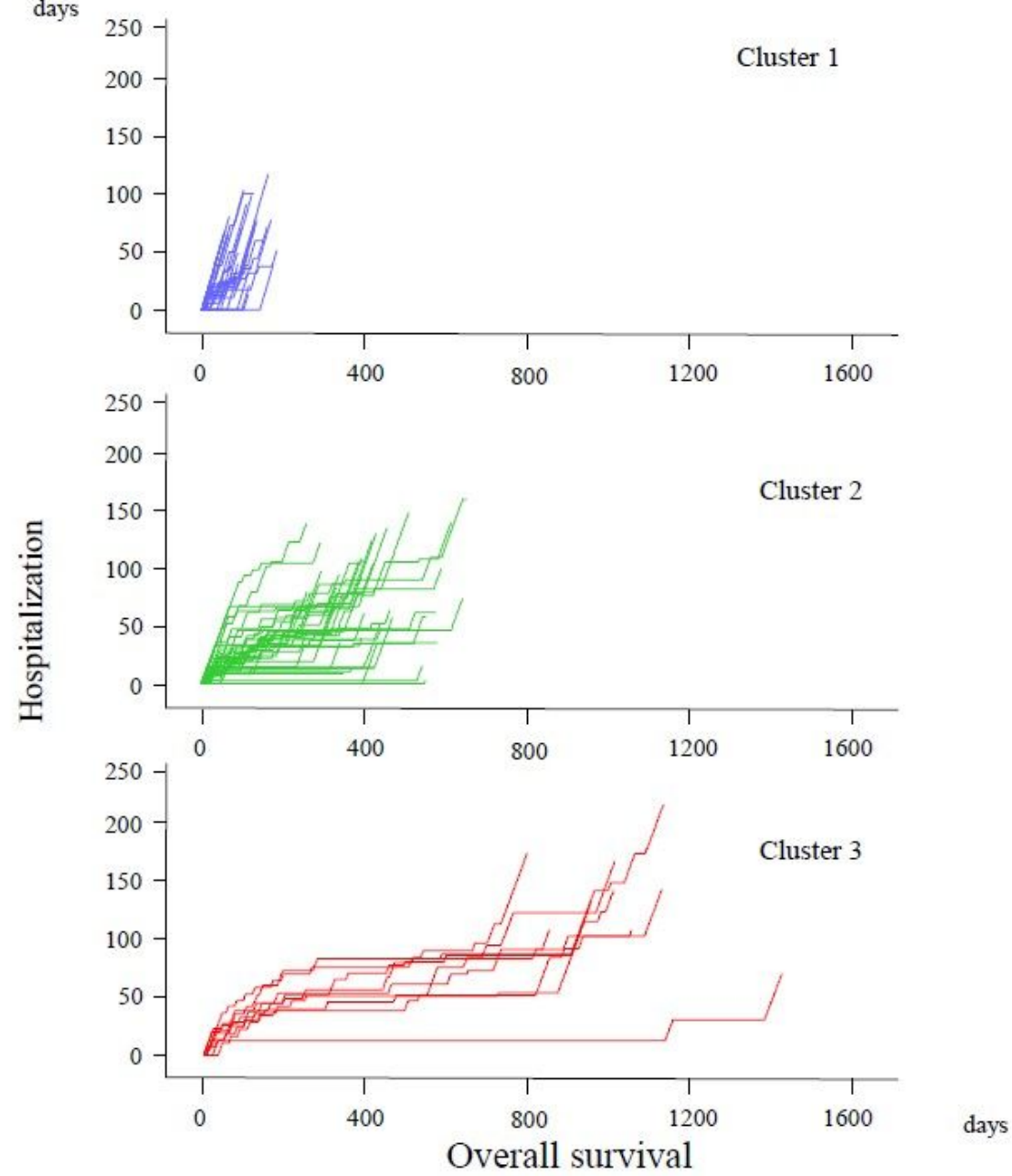

\section{Figure 5}

Trajectories of hospitalization vs. overall survival in three groups of patients with incurable gastric cancer 